\title{
The Research on Financing Channels of Industrial Enterprises Taking the Development of Industrial economic of Jiangsu Province for Example
}

\author{
Shi-hua $\mathrm{LI}^{1,3, a}$, De-xiang Zhou ${ }^{2, b}$ and Wei Zhang ${ }^{3, c}$ \\ ${ }^{1}$ School of management and engineering, Nanjing University, Nanjing 210093, China \\ ${ }^{2}$ School of Marxism, Hohai University, Nanjing 210098, China \\ ${ }^{3}$ Postdoctoral Workstation, Govtor Capital, Nanjing 210009 China \\ alishihua88@163.com, b'zhoudexiang7428@sina.com, 'lishihua88@sina.com
}

Keywords: Financing channel; Credit Financing; Debt Financing; Lease Financing; Private Equity

\begin{abstract}
Taking the development of industrial economic in Jiangsu Province for example, introducing the status of industrial enterprises, this work gives total analysis of various financing pattern: credit financing, debt financing, financing lease and private equity in Jiangsu. And according to concrete data, indicate the industrial enterprises constraint in industrial financing channels. Finally, suggestions on how to explore financing channels were given systematically.
\end{abstract}

\section{Introduction}

The industrial economies of Jiangsu Province are holding out a cheerful prospect: the scales are expanding constantly; economic operational qualities are improving significantly; and the structural adjustments are advancing orderly, as shown in Table 1.

Table 1. The growth conditions of Jiangsu Province's industrial added value (IAV) of the industrial enterprises above designated size

\begin{tabular}{|c|r|r|r|r|c|c|c|c|}
\hline & 2004 & 2005 & 2006 & 2007 & 2008 & 2009 & 2010 & 2011 \\
\hline IAV & 6447.48 & 8118.99 & 10309.22 & 12926.87 & 14758.95 & 16727.14 & 21224 & 25034.8 \\
\hline Growth rate & $38.04 \%$ & $25.93 \%$ & $26.98 \%$ & $25.39 \%$ & $14.17 \%$ & $13.34 \%$ & $26.88 \%$ & $17.96 \%$ \\
\hline
\end{tabular}

The current price output value and sales value reached 10.9 trillion RMBs and 10.7 trillion RMBs, respectively. Total industrial added value and the scale of production and sales continue to remain first in the country. The enterprises above designated size had finished IAV 2503.48 billion RMBs, accounting for more than $11 \%$ of the national total-the total proportion ranking first in the country. Based on a variety of survey since the late 1990s, the financing difficulties have become the biggest obstacle restricting the development of China's industrial enterprises. In Jiangsu province industrial enterprises, primarily small and medium enterprises, and many industrial enterprises exist defect in such respect as weak competitiveness, the lower quality of management and lower credibility. They not only lack enough assets that can be pledged, but also have difficulties in obtaining external credit guarantee from other institutions and enterprises. At the same time financial institutions generally are wary of the small and medium-sized industrial enterprises, and so the financing problem of the industrial enterprises was born.

The financing predicament has become the bottleneck of the development of small and medium-sized industrial enterprises (SME) in China, which has been becoming a serious impact on the expansion and technology upgrades of SME, and also reduces the distribution efficiency of social funds. Based on the analysis of the financing status of SMEs in Jiangsu Province, this article researches the deep-seated reasons for its financing difficulties, in order to provide a scientific basis for the formulation of policies and arrangements to ultimately promote socio-economic development in our province. 


\section{Total analysis of various financing pattern}

\subsection{Credit Financing}

The credit financing consist primarily of ordinary loans (ordinary commercial bank loans), bill financing, entrusted loans, and so on. According to the term of the loan the ordinary commercial bank loans is divided into short-term loans and long-term loans, medium and long-term bank loans have absolute advantage in the pattern of credit financing, account for more than 90 percent of total loans. In 2010 in Jiangsu Province, short-term loans and medium-and-long-term loans accounted for up to $97.17 \%$, entrusted loans $2.83 \%$, bill financing only $0.05 \%$. Overall, from 2006 to 2010, the overall credit financing in Jiangsu Province presents an increasing trend year by year, and to the end of 2010, the total credit facilities of Jiangsu Province amounted to 4.204208 trillion RMBs, an increase of approximately $19.28 \%$ over the previous year.

Table 2. Distribution of credit facilities in Jiangsu Province from 2006 to 2010 (billion, \%)

\begin{tabular}{|l|l|l|l|l|l|l|l|l|l|}
\hline \multirow{2}{*}{ year } & \multicolumn{2}{|c|}{$\begin{array}{c}\text { The balance of } \\
\text { short-term loans }\end{array}$} & \multicolumn{2}{c|}{$\begin{array}{c}\text { The balance of } \\
\text { long-term loans }\end{array}$} & \multicolumn{2}{c|}{ Entrusted Loan } & \multicolumn{2}{c|}{ Bill financing } & \multirow{2}{*}{ sum } \\
\cline { 2 - 9 } & amount & proportion & amount & proportion & amount & proportion & amount & proportion & \\
\hline 2006 & 928.157 & 50.27 & 739.533 & 39.86 & 176.361 & 9.55 & 2.334 & 0.13 & 1846.385 \\
\hline 2007 & 1104.637 & 50.04 & 961.114 & 45.54 & 134.784 & 6.11 & 6.944 & 0.31 & 2207.479 \\
\hline 2008 & 1224.548 & 46.87 & 1162.893 & 44.51 & 220.314 & 8.43 & 4.895 & 0.19 & 2612.650 \\
\hline 2009 & 1472.365 & 41.77 & 1817.356 & 51.56 & 232.695 & 6.60 & 2.17 & 0.06 & 3524.586 \\
\hline 2010 & 1768.903 & 42.07 & 2316.345 & 55.10 & 116.702 & 2.78 & 2.258 & 0.05 & 4204.208 \\
\hline
\end{tabular}

\subsection{Debt Financing}

Debt financing means that enterprises raise money through loaning from a bank or non-bank financial institutions, or issuing bonds. Among Debt financing the direct financing includes debt financing instruments of non-financing enterprise in the inter-bank bond market (debt financing instruments for short), enterprise bond and, corporate bond, etc. From 2006 to 2011, the total issuance of bond financing instruments and enterprise bond accounted for more than $90 \%$ of the debt financing scale of Jiangsu Province. Although the corporate bond issuance also showed an increasing trend year by year, in general, the issuing size is small comparatively; the proportion has been less than 5\% except in 2011.

Table 3. Distribution of debt facilities in Jiangsu Province from 2006 to 2011 (billion, \%)

\begin{tabular}{|c|c|c|c|c|c|c|c|}
\hline \multirow{2}{*}{ Year } & \multicolumn{2}{|c|}{$\begin{array}{c}\text { debt financing } \\
\text { instruments }\end{array}$} & \multicolumn{2}{c|}{ enterprise bond } & \multicolumn{2}{|c|}{ corporate bond } & \multirow{2}{*}{ sum } \\
\cline { 2 - 6 } & amount & proportion & amount & proportion & amount & proportion & \\
\hline 2006 & 10.25 & 96.0 & 0 & 0 & 0.43 & 4.0 & 106.8 \\
\hline 2007 & 20.87 & 82.6 & 3.95 & 15.6 & 0.44 & 1.7 & 252.6 \\
\hline 2008 & 18.34 & 64.0 & 9.20 & 32.1 & 1.10 & 2.8 & 286.4 \\
\hline 2009 & 168.0 & 19.6 & 48.30 & 56.4 & 2.00 & 2.3 & 857.0 \\
\hline 2010 & 38.63 & 54.4 & 30.28 & 42.6 & 2.14 & 3.0 & 710.5 \\
\hline 2011 & 65.49 & 63.9 & 29.31 & 28.6 & 7.70 & 7.5 & 1025.0 \\
\hline
\end{tabular}

\subsection{Financing lease}

From 2006 to 2010, in Jiangsu Province finance lease balances have been being increasing year by year, from 873 million RMBs of the year 2006 to 6.822 billion RMBs of the year 2010. In 2010, finance lease balances increased by 3.331 billion RMBs compared with the year 2009, year-on-year growth of $95.42 \%$. 
Table 4. The finance lease situation in Jiangsu Province from 2006 to 2011(billion, \%)

\begin{tabular}{|c|c|c|c|}
\hline year & $\begin{array}{c}\text { The balance of finance } \\
\text { lease }\end{array}$ & $\begin{array}{c}\text { Added over the previous } \\
\text { year }\end{array}$ & annual growth rate \\
\hline 2006 & 0.873 & & $28.75 \%$ \\
\hline 2007 & 1.124 & 0.251 & $63.35 \%$ \\
\hline 2008 & 1.836 & 0.712 & $90.14 \%$ \\
\hline 2009 & 3.491 & 1.655 & $95.42 \%$ \\
\hline 2010 & 6.822 & 3.331 & \\
\hline
\end{tabular}

\subsection{Financing of private equity}

From 2006 to 2011, in Jiangsu Province, financing of private equity showed a growing trend as a whole, newly increased amount of private equity reached from 456 million RMBs in 2006 to 7.76 billion RMBs in 2011. Except for the 2010's newly increased amount 6.817 billion RMBs, which is slightly lower than the new amount 1.135 billion RMBs of the year 2009 compared to the same period last year, other years new investment quota exceeded last year. As of the end of 2011, the amount of equity financing added up to 7.76 billion RMBs, a year-on-year growth of $13.83 \%$.

Table 5. Jiangsu's private equity financing from 2006 to 2011(a hundred million, \%)

\begin{tabular}{|c|c|c|}
\hline year & The amount of financing & Year-on-year growth \\
\hline 2006 & 4.56 & 0 \\
\hline 2007 & 15.13 & $231.80 \%$ \\
\hline 2008 & 26.23 & $73.36 \%$ \\
\hline 2009 & 79.52 & $203.16 \%$ \\
\hline 2010 & 68.17 & $-14.27 \%$ \\
\hline 2011 & 77.60 & $13.83 \%$ \\
\hline
\end{tabular}

\section{Structural analyses of the various types of financing}

As is shown from Table 6 according to the financing distribution of SMEs. Firstly, the source of funding for SMEs is still single, relying heavily on banks. From 2006 to 2010, external financing mainly rely on bank credit financing, accounting for about $95 \%$ of the total financing. Secondly, the scale of direct financing is smaller. In China more stringent rules on equity financing, bond financing were enacted, and a higher threshold were established. So the majority of small and medium enterprises in Jiangsu Province cannot meet the requirements. From 2006 to 2010, due to the higher threshold for debt financing, it is always less than $5 \%$ of the financing scale. In recent years the size of private equity financing are substantially increasing, reaching about 7.952 billion RMBs, up 5.329 billion RMBs on last year's corresponding period. The main reason is that the Growth Enterprise Market (GEM) in China was officially launched, widening the exit channels for the private equity investment, which promote the rapid development of private equity investments. But the whole financing scale is too small, accounting for less than $1 \%$ of the financing of SMEs, to support the SMEs better in Jiangsu province.

Table 6. The amount of financing structure of distribution in Jiangsu Province (billion, \%)

\begin{tabular}{|c|c|c|c|c|c|c|c|c|}
\hline \multirow{2}{*}{ year } & \multicolumn{2}{|c|}{ Credit financing } & \multicolumn{2}{c|}{ Debt financing } & \multicolumn{2}{c|}{ Finance leases } & \multicolumn{2}{c|}{ Private equity } \\
\cline { 2 - 9 } & amount & proportion & amount & proportion & amount & proportion & amount & proportion \\
\hline 2006 & 1846.385 & 99.35 & 10.68 & 0.57 & 0.873 & 0.05 & 0.456 & 0.03 \\
\hline 2007 & 2207.479 & 98.75 & 25.26 & 1.13 & 1.124 & 0.05 & 1.513 & 0.07 \\
\hline 2008 & 2612.65 & 98.75 & 28.64 & 1.08 & 1.836 & 0.07 & 2.623 & 0.10 \\
\hline 2009 & 3524.586 & 97.32 & 85.70 & 2.37 & 3.491 & 0.10 & 7.952 & 0.22 \\
\hline 2010 & 4204.2 .08 & 98.03 & 71.0 .5 & 1.66 & 6.8 .22 & 0.16 & 6.817 & 0.16 \\
\hline
\end{tabular}

\section{Industrial enterprises constraint analysis of industrial financing channels}

To solve the problem of financing difficulties of industrial enterprises, especially the outside source of financing difficulties, we have to analyze and study the deep-seated reasons. Only based on an 
analysis of the internal factor and external factor of financing obstacles, the essence of the problem can be relatively comprehensively understood. The internal reasons-endogenous obstacles-includes: SMEs's missing credit, unclear property rights, chaotic internal governance, information asymmetry, and so on. The external factors-exogenous obstacles based on the China's existing financial system-are that financing and policy environments in favor of SMEs have not yet formed or were not imperfect.

From the perspective of the enterprises themselves, the ability of anti-risk of small and medium-sized industrial enterprises is weak; awareness of credit shallow; financial management not standardized; industrial level not high. From the respect of financing channels, the financing channels for SMEs is single; higher financing costs are higher; direct financing are not ideal; financial institution only serving SMEs are penurious. From the relevant laws, regulations, and policy, the financial policy and the legal system promoting the development of SMEs is not perfect; credit guarantee system of SMEs is not perfect; slower introduction of financial innovation policies is comparatively slower; and financial supervision and control is too severe.

\section{Conclusion and suggestions}

Although Jiangsu's industrial economic have attained a certain degree of prosperity, meanwhile, a lot of financing difficulties and constraints are still existing; the financing structures are not rational comparatively. In order to explore new financing channels to promote the development of industrial economics, suggestions should be as follows:

Expanding credit support: Banks and other financial institutions should be to start strategic transformation, and duly lower access standard to credit for SMEs. Establish the standardized credit business processes and improve the operational efficiency of the business of small and medium-sized industrial enterprises credit. Further improve the credit guarantee mechanism.

Promoting the development of direct financing: During promoting the construction of regional capital markets, the regional government, financing policies must be based on national, give full play to the service function of capital markets as per relative financial policies of our country, and explore new financing channels for SMEs which cannot reach the listing standards of Main Board and Second Board Market.

Strengthening the financial service innovation of commercial banks:The commercial banks must adhere to the essential requirements of the real economy, continue to strengthen service innovation, improve service levels, achieve common survival and common prosperity between the financial and the real economy, and actively promote the normal functioning of the socio-economic system.

Implementing various preferential taxation policies and expanding financial support: Tax incentives, common tools used by many countries to reduce the tax burden, can guide the rational allocation of resources, promote economic restructuring, foster and strengthen the economy, and promote social harmony and stability. As to financial support, increase the investment in the construction of technical innovation environment; constantly improve science and technology intermediary service system, construct a technological innovation system realizing the combination of production study and research based on enterprises as the main body, so as to comprehensively promote Jiangsu technological innovation system. Meanwhile, establish a diversified investment mechanism, especially venture capital investment mechanism.

\section{Acknowledgements}

This work was financially supported by: Govtor Capital (JSGOVTOR2012); "Doctor clustering scheme of enterprises in Jiangsu Province-the category of Enterprise Postdoctoral"; Meanwhile, it was supported by the scientific research innovation project in Jiangsu Province (CXZZ12-0222). 


\section{References}

[1] LI Ping, Tang Qing-quan. Comparative Analysis of Financing Channels between Silicon Valley and Zhongguancun. Journal of the graduates VOL.32 (3).(2011), p.165-176.(In Chinese)

[2] LI Liu-yu. A single financing channel is not good for China economic transition. Journal of International Financing. (2012), p. 28-31. (In Chinese)

[3] Kuznets. S. Economic growth of nations [M]. Cambridge MA. Harvard University Press.1971.

[4] Casamatta, C Atherine. Financing and advising: optimal financial contracts with venture capitalists. Journal of Finance, 2003, 58 (5): 2059-2086.

[5] HELLMAN T, PURI M. Venture capital and the professionalization of start-up firms. Journal of Finance, 2002, 57: 169-197. 